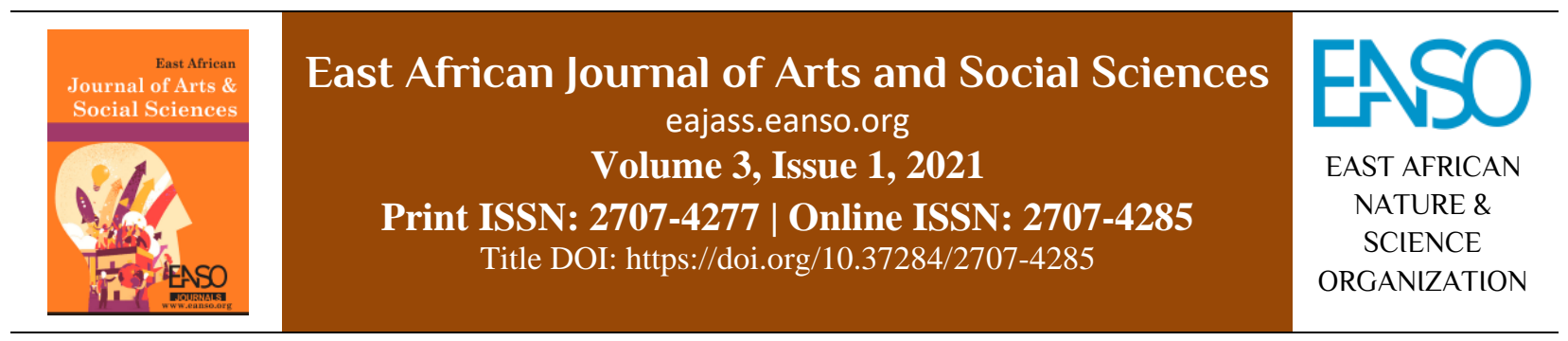

Original Article

\title{
Effects of Drug Abuse in Schools and Homes in Kenya.
}

\author{
Dr. John Ndikaru wa Teresia, PhD ${ }^{1 *}$ \\ ${ }^{1}$ Department of Criminology and Legal Studies, The Technical University of Kenya, P. O. Box 57173 - 00200, Nairobi, Kenya. \\ *Correspondence email: jndikaru@gmail.com.
}

Article DOI: https://doi.org/10.37284/eajass.3.1.428

\section{Article history: ABSTRACT}

05 October 2021 The intensity of drug abuse has been a major concern in recent years. It has invaded homes, schools, and workplaces, affecting individuals of all ages and

Keywords: classes (UNDCP, 1992). According to the World Drug Report 2007, approximately 200 million people, about $5 \%$ of the world's population aged

Adolescent, between 15 and 64 years, have used drugs at least once in the previous months. Drug, According to surveys of adolescent students in Nova Scotia in Canada, carried Tobacco,

Cannabis, Quantitative, Alcohol,

Qualitative,

Home,

School,

Mitigation,

Guardian used alcohol, tobacco, and cannabis. The researcher used a survey study. The respondents were drawn from stratified regions. The selected regions were Coast, Nyanza, and Nairobi. The schools sampled were registered with the ministry of education science and technology. They were categorized into national, county, and sub-county schools, boys and girls, mixed boarding, and mixed schools. Questionnaire and in-depth interviews were used to collect quantitative and qualitative data from students and teachers.

\section{APA CITATION}

wa Teresia, J. N. (2021). "Effects of Drug Abuse in Schools and Homes in Kenya. East African Journal of Arts and Social Scien 3(1), 170-180. https://doi.org/10.37284/eajass.3.1.428

\section{CHICAGO CITATION}

wa Teresia, John Ndikaru. 2021. "Effects of Drug Abuse in Schools and Homes in Kenya". East African Journal of Arts and Social Sciences 3 (1), 170-180. https://doi.org/10.37284/eajass.3.1.428

\section{HARVARD CITATION}

wa Teresia, J. N. (2021) "Effects of Drug Abuse in Schools and Homes in Kenya", East African Journal of Arts and Social Sciences, 3(1), pp. 170-180. doi: 10.37284/eajass.3.1.428.

\section{IEEE CITATION}

J. N. wa Teresia, "Effects of Drug Abuse in Schools and Homes in Kenya", EAJASS, vol. 3, no. 1, pp. 170-180, Oct 2021.

170 This work is licensed under a Creative Commons Attribution 4.0 International License. 


\section{MLA CITATION}

wa Teresia, John Ndikaru. "Effects of Drug Abuse in Schools and Homes in Kenya". East African Journal of Arts and Social Sciences, Vol. 3, no. 1, Oct 2021, pp. 170-180, doi:10.37284/eajass.3.1.428.

\section{INTRODUCTION}

Drug abuse has been defined as a selfadministration of drugs for non-medical reasons, in quantities and frequencies which may result in physical, social, and or emotional harm (Olatuwra and Odejide, 2006). Drug and substance abuse is a global phenomenon and an ever-expanding invasive problem in the world today. It affects almost every country, although its extent and characteristics differ from region to region. A study conducted by Edwards (1979) among American youth found that a great deal is known about what is abused but less comprehended. He suggested that it was not only important to know what is abused but also know why it is abused so that intervention strategies could be used to reverse the situation.

They found that the most commonly abused drugs were salicylate, any of the group of analgesics, or painkilling drugs that are derivatives of salicylic acid. They also found that the current and lifetime use of alcohol and tobacco was significantly more common among the males and among those in rural schools. They further indicated that, for the majority of the students, initiation into drug use started at a very early age (under 14 years). A study carried out among Zambian pupils found that while up to $10 \%$ of the female pupils experimented with cannabis, only male students tended to become regular users (Guy 2004). Guy (2004) further states that pupils who abused drugs were irregular in schools, which affected their performance greatly.

In Uganda, a study noted that among the youth, $19 \%$ of the Primary school pupils and about $33 \%$ of secondary schools smoked cigarettes (Olatuwara and Odejide 1971). This was attributed to a lot of tobacco products being advertised in relation to style/fashion and due to influence. The mean age for smoking was 13.4 years, with an average of 6 to 22 years in Jinja District. In the same country, a crosssectional study carried out among 13-15-year-old found that $17.5 \%$ reported having smoked tobacco, with $37.9 \%$ of them trying or starting smoking before the age of 10 (Mpabulungi and Muula, 2004).
European schools' project on alcohol and other drugs revealed that $37 \%$ of 10th-grade students in the 30 participating European countries had smoked a cigarette in the past 30 days, $61 \%$ had used some illicit drugs other than Marijuana (Hibbel, Anderson, Bjarnason, Morgan and Narusk, 1995). Fatoye and Marakinyo (2002) studied drug abuse amongst 567 primary school pupils in rural and urban communities in South Western Nigeria

A preliminary survey of drug abuse was conducted among primary school pupils in Kenya and the results of the study confirmed that drug abuse was quite prevalent among Primary pupils. For instance, up to $10 \%$ of students drink alcohol more than three times a week and nearly $14 \%$ had smoked cannabis (bhang), 16\% admitted taking other drugs, especially tranquilizers, in order to feel high. The study further revealed that the problem was more acute in urban schools compared to rural schools.

\section{Statement of the Problem s}

Today, various stakeholders have considered education as a fundamental way that promotes economic, social, and political development. It opens new perspectives, inspires people, and offers openings for active contribution in growth by offering knowledge, attitudes, and skills that are compatible with workable development.

In pursuit of these objectives, the Government of Kenya had accepted a strategy of offering basic education for all citizens, notwithstanding their economic, social, and cultural position. This is a move towards an understanding of Universal Primary Education (UPE) and Learning for all. Education is one of the objectives captured in Kenya's vision 2030. Nonetheless, this aim is likely not to be accomplished partly due to drug abuse. Drug addicts often miss schools and also decline from school. They roam and tom of events of drug abuse that unravel in homes and schools is wanting.

The national authority for the campaign against alcohol and drug abuse (NACADA) has been at the forefront in fighting such vices in society through the implementation of the policies, raising 
awareness, participation activities that help restrain the abuse of drugs in schools and at homes amongst others. A survey done by NACADA shows that the vulnerable group is the ages of 13 and 15 terming the period most likely for children to initiate alcohol and substance abuse. Several factors contribute to such behaviors; curiosity, acceptance by peers, and ignorance as to the dangers of drug abuse, and having a lot of pocket money as the main reasons for the abuse of drugs. Both schools and guardians at home face challenges trying to curb such vices because they are not sure of the approach and mitigation practices to help reduce the effects since the intensity is normally felt when it's at its peak. The effect of drug abuse at home and school is a point of focus for this study with a better understanding of the ground.

\section{EMPIRICAL LITERATURE REVIEW}

\section{The Predictors of Drug Abuse among High School Students}

The easy accessibility of drugs is considered a critical factor in encouraging high school students to use drugs. Njoki (2013) established that most students in secondary school fall prey to experimentation with drugs due to the easy availability of drugs and substances. This is especially evident considering that most of the drugs that students abuse are locally manufactured, such as alcohol and bang. For instance, in major cities such as Kisumu, the busy bus stop shops within the city center are renowned dens for drugs. The rate of circulation of hard drugs in Kenya is also high considering the strategic location of the country, which makes it a perfect conduit for international drug traffickers to transport drugs from Asia and Latin America. Ngesu (2017) notes that alcohol is the commonly abused drug amongst high school students because it is normally sold legally since it has been accorded commodity status.

Most secondary school students are in the adolescent age, which is a critical developmental stage that is characterized by many social and psychological tensions. Njeri and Ngesu (2014) concur that the age of the students in secondary school is also a contributing factor. Most of the students are in their adolescence, which is a transition stage from childhood to adulthood. This stage is characterized by various social and psychological challenges as the students seek to find or understand their identity. The process of understanding one's identity involves curiosity, which leads some to experiment with drugs.

The home environment in which teenage children are brought up, largely characterised by parental influences, also contributes to the uptake of drugs and substances by high school students. Rugendo (2016) pointed out that parental influence also plays a significant role in determining whether secondary school students indulge in drugs. Children who come from families where parents use alcohol and other forms of drugs are highly likely to imitate their parents. Some parents contribute to the problem by providing their children with excessive cash in the form of pocket money and travel allowances, which they instead use to purchase drugs.

Poor relationships between the adolescent students and their parents or guardians also contributed to the use of drugs and substances. Some students adopted the use of drugs as a way of rebelling against their parents or guardians (Cheloti and Gathumbi, 2016). The rebellion, in this case, is fostered with strict parenting in which case the children used to befriend their parents or guardians and resort to using drugs as a way of asserting their maturity, freedom, and independence. The adolescent students, therefore, use drugs and substances as their way of releasing pressure from their parents or guardians (Rugendo, 2016).

According to Makau, Kaaria, and Katiba (2019), absent parents also determined whether high school students used alcohol and other drugs. Without parents' surveillance and availability to provide guidance, students found it very easy to use drugs even after school. Joseph (2019) established that single parenting resulting from separation and divorce leads to dysfunctional families whereby the parent left with the adolescent may not be able to provide guidance and surveillance that they need to avoid experimenting with drugs.

Single parents who are also breadwinners lack adequate opportunities for supervising their children. Due to lack of supervision, the children may be attracted to the wrong company, and end up using drugs as a way of drawing the attention and admiration of peers who are using and abusing 
substances (Cheloti and Gathumbi, 2016). In particular, Rugendo (2016) points out that girls from single-parent families are highly likely to abuse drugs as compared to girls from families with both parents. Besides, most teenage girls who use drugs have suffered some form of rejection from their family members. The rejection pushed them to find solace from their peers, which makes them susceptible to accepting requests to experiment with drugs and substances.

The school environment also determines whether or not students will be inclined or incentivized to use drugs and substances. Odhiambo, Sifuna, and Kombo (2019) notes that drug use amongst secondary school children is also influenced by the preparedness of school administrations to erect adequate controls for curbing the usage of drugs in school. While schools need to establish no-tolerance stances against drug use and drug users, it is important to remember that harsh treatment, highhandedness, and the lack of opportunity for students to exercise a considerable measure of freedom can easily result in stress that makes those who cannot cope to resolve to drug use. There are also cases where the school administrations are so lax to an extent that some members of the staff or the subordinate staff smuggle and sell drugs to the students.

The promotion of drugs such as alcohol through the media encourages adolescent students to experiment with drugs. Ngesu (2017) also considers advertisement a key contributor of particularly alcohol amongst high school male students. This is due to the fact that most advertisements of alcoholic products target men, portraying a notion that alcohol taking is a masculine thing. At their adolescent stage, these students are yet to become emotionally mature to sift through the superfluous messaging of an advertisement and make constructive decisions regarding their lives. Those students who are able to ignore the adverts still end up convinced that a moderate intake of alcohol is good for their health.

Rugendo (2016) acknowledges the fact that, as a country, Kenya is fast recognizing the rampant use of drugs and other substances in secondary schools. Some of the drugs that are commonly used by secondary school students include cigarettes, alcohol, and bang. These drugs are normally consumed in school during weekends or after class hours; there is also increased intake of the drugs during exam periods as a way of relieving stress that is associated with examinations. This indicates that when students are not supervised during their leisure time, such as weekends, they end up engaging in negative social behavior that makes the access and use of drugs and substances a necessary pass time.

Peer influences also significantly contribute to the usage of drugs and substances amongst high school students. Njeri and Ngesu (2014) cite peer pressure as the key predictor of alcohol and drug use amongst students in secondary schools in Kenya. Peer pressure is particularly significant at the initial stages of drug use when the adolescent seeks to belong to a particular clique whose way of leisure involves taking some particular drugs. Abur (2014) established that the youth access illegal drugs through their peers, and most of these drugs they cannot purchase through ordinary means. Their peers supply them with the drugs directly or provide them with information on how and where they can obtain them. In most instances, the non-socialized youth who is seeking to belong lacks the resolve to say no. Rugendo (2016) further notes that peer groups also provide newbies with models of drug usage and also teach them how, when, and where they can use the drugs.

Secondary school students are teenagers and most of them are unaware of the danger of experimenting with drugs. Joseph (2019) cited ignorance as a cause for drug use among adolescents in secondary schools. The students experimented with drugs with the objective of acquiring short-term effects such as feeling high, oblivious to the long-term effects that awaited them with continued use of the drug, such as addictions. Makau, Kaaria, and Katiba, (2019) concur that most youths engage in drug use without being aware of the various dangers that are associated with the vice. This is evident considering the statistics by the National Institute of Drug Use which indicated that about 80 percent of students in schools were unaware of the illicit drugs whereas only 6 percent knew the harmful effects of abusing drugs. This implied that most students indulge in alcohol and drug use without knowing the dangers that are associated with the vice. 
According to Odhiambo, Sifuna, and Kombo (2019) trying new things or different behavior is a rather natural process for many adolescents and at times reflects in terms of seeking popularity with peers, gaining acceptance, developing a sense of identity, autonomy, and maturity, and/or, separating from parents. Adolescents consider engaging in alcoholism and abusing drugs and substances as a functional way of seeking and attaining popularity, acceptability, maturity, and independence. This leads them to get into addiction if interventions are not undertaken to stop them from taking drugs.

The social-economic background of the students is another predictor of susceptibility to drug use. Odhiambo, Sifuna, and Kombo (2019) low socioeconomic factors were associated with greater use of cigarettes, alcohol, and cocaine among adolescent students. students from homes with financial difficulties also lived-in poor neighborhoods where access to drugs was easy and possibly spent their leisure time with peers who are already using drugs. teenagers from low-income backgrounds were susceptible to drug use because they considered it providing them with an escape from the harsh economic realities at home and school.

Cheloti and Gathumbi (2016) established that families with low socioeconomic status and large sizes increased the probability of drug and substance abuse among teenagers who came from them. The quest to use the drug and other substances were seen as a solution to problems regarding the provision of basic needs, family dysfunctions. Drug use helps adolescent students to avoid the pressures of life and other problems. The consumption of drugs, therefore, becomes a defense mechanism against a world that they consider unfair and also do not understand.

\section{Effects of Drug use amongst High School Students}

The secondary school students who use drugs and substances experience challenges in regards to their academic performance. Njoki (2013) notes that drug and substance abuse amongst high school students manifests in the form of declining academic performance. This is closely related to absenteeism from school and other school-related activities and increased the potential of dropping out of school. Abur, (2014) established that students who use drugs have a low commitment to their education and also have a higher truancy rate. The behavioral and cognitive problems that are associated with alcohol and drug use interfere with the performance of the students in academics and also affect their capacity to learn from their classmates.

According to Joseph (2019), the use of drugs and substances causes students to become sleepy in the classroom and are therefore unable to concentrate during lessons. They may choose to absent themselves from class to avoid detection by students or teachers. They also become poor managers of their time and may be found looking for drugs instead of concentrating on their assignments or revision work in class. They, therefore, post poor performance when it comes to exams.

The effects of drug use amongst high school students include unrest in secondary schools. Njoki (2013) established that the lawlessness and unrest in secondary schools in Kenya can be attributed to the use of drugs such as bang, alcohol, and experimenting with hard drugs such as heroin, cocaine, and mandrax that get into the local market via illicit trafficking. Kimanthi and Thinguri (2014) note that drug use is a predictor of aggressive behavior amongst the youth and is associated with the violence that leads to strikes and the destruction of property in schools.

The abuse of drugs and substances amongst secondary school students also comes with myriad health challenges and complications. Njeri and Ngesu (2014) note that alcohol and drug use amongst high school students leads to health challenges that are characterized by physical injuries that may lead to disabilities. The effects of an overdose of drug intake may also be injurious to their physical health system. The students were also at a high risk of contracting HIV/AIDS or any other sexually transmitted diseases. Due to risky health behaviors that they may engage in while using drugs. According to Abur (2014), there are various pharmacological risks factors that emerge as individuals increase the use of drugs and substances. This is particularly evident with the use of drugs such as morphine, nicotine, cocaine, and 
amphetamine that may affect the brain in particular ways.

Rugendo (2016) established that youths who abuse drugs are highly susceptible to mental health problems such as stress, depression, withdrawal, and developmental lags. Youth who abuse substances are at significantly high risk for mental health problems such as personality disorders, conduct problems, suicides, and attempted suicides. For instance, the use of marijuana is associated with the interference of the students' short memory, psychomotor skills, and general learning. Students' motivation, emotional and psychosexual development may also be negatively affected by drug abuse. Ngesu, (2017) established that alcohol usage affected the capacity of one to make judgments and decisions, leading youth to indulge in risky sexual behavior. They are as a result exposed to sexually transmitted diseases. This has a ripple effect on the country's economy since the treatment of the addicted youth at the rehabilitation centers is normally reliant on public funding.

Secondary school students who abuse drugs end up destroying crucial social relationships in their lives, which manifests in terms of social stigma. Odhiambo, Sifuna, and Kombo (2019) observe that the abuse of alcohol and other drugs can lead to family crises and endanger various aspects of family life, in some cases resulting in family dysfunction. Students who abuse drugs are at constant loggerheads with their other family members because their behavior affects their parents and siblings, especially if they have to steal from them to fund their addiction or force them to incur a medical bill for injuries they acquire from their drinking or smoking adventure. The student may even decide to run away from home as a way of punishing their family members or escaping their wrath.

The use of drugs and substances by adolescent students is also associated with the degree of bonding with conventional institutions. Students that have failed to develop and maintain the relationship with other peers and their teachers or are not engaged in the school activities are highly likely to resort to drugs and substance abuse (Cheloti and Gathumbi, 2016). Whenever adolescents are disengaged from their environment or communities, they tend to feel unsafe in them and find solace in abusing drugs. Contrarily, students who are actively engaged in the community at school and church levels, for instance, are highly unlikely to resort to drug and substance abuse. Therefore, schools and communities play an integral role when it comes to enacting the protective factors that engage young people and encourage them to avoid drugs and other problematic social behavior (Rugendo, 2016).

Joseph (2019) notes that students who abuse drugs were always involved in indiscipline issues, such as fighting, absenteeism from class, sneaking from school, refusing to do assigned chores, and even refusing to take care of their own personal hygiene. In this way, they destroy their relationship with peers at school and their teachers as well. Cheloti and Gathumbi (2016) observe that the use of drugs and substances amongst adolescent students is also associated with stigma. Since the youth are engaging in behavior that is considered anti-social, they are likely to be relegated to the periphery of the social sphere as misfits. The stigma weighs down on the young persons and particularly those of want to stop abusing drugs and may have counterproductive effects. This is in the sense that the addicted youth may shy away from seeking help out of the fear of being judged by society.

Students who abuse drugs are highly likely to get involved in delinquent behavior. Njeri and Ngesu (2014), notes that drug and substance abuse is a major cause of delinquent behavior among students in high schools. It leads to arrests, adjudication, and intervention by the juvenile justice system. This is because the youth abusing drugs are highly likely to be involved in criminal activities such as physical or sexual abuse, possession and use of hard drugs, prostitution, drug trafficking, gangs, and homicides amongst many other social vices that may call for the intervention of the criminal justice system.

Furthermore, students who use drugs are prone to emotional and psychological challenges. Rugendo (2016) pointed out that some psychological traits that are associated with drugs and substance abuse amongst adolescent students include low selfesteem, poor behavioral self-control, and low assertiveness. Odhiambo, Sifuna, and Kombo (2019) established that teenage girls who come from 
families with educated parents were highly unlikely to abuse drugs as compared to those who come from families with less-educated parents. Parents with low education levels used coercive strategies to discipline their children, which eventually put them in abnormal and anti-social behavior, including drug use. This demonstrated that the level of education of parents influenced the proper upbringing of children and therefore dissuaded them from experimenting with drugs and substances.

Rugendo (2016) established secondary students from urban settings were highly likely to abuse drugs and substances as compared to their counterparts from the rural areas. This was explained by the fact that in most cases the urban setups have a great influence on teenagers occasioned by the exposure to the urban lifestyle. Rugendo (2016) notes that drugs and substance abuse have translated into an increase in the rate of criminal activity at the school, occasioned by stealing and strikes.

Cheloti and Gathumbi (2016) pointed out that the community around the secondary school can also influence the behavior of students and encourage or discourage them to use drugs and substances. This is evident considering that, in most cases, the alcohol and drugs that are consumed by the students are sourced from the community around the school. This makes it imperative for the school administration to engage the surrounding community in drug prevention programs as a way of cutting critical supply channels that students may be using to access drugs and sneak them into school.

\section{THEORETICAL FRAMEWORK}

\section{Modified Social Stress Model}

The modified social stress model was used in this study to understand the use of alcohol and illicit drugs amongst adolescents in high schools in Kenya. The model was developed by Rodes and Jason in 1998 and was later modified by the World Health Organisation (WHO) to include the effects of drug abuse, individual responses to drugs exposure, and the social, environmental, and cultural factors associated with the drug abuse (Shukla, 2005; Abraham, Pamela, and Kimani, 2012).
Studies have revealed that the prevention of substance use and abuse should consider identifying the factors increasing the risk of using and abusing drugs and developing ways of reducing the impact of those factors (Njoki, 2013; Abur, 2014; Rugendo, 2016). The modified social stress model reiterates that there are some factors that promote drug use, which are referred to as risk factors. They are also factors that discourage people from abusing drugs, and they are referred to as protective factors. Therefore, to increase the health of families and communities, the reason needs to be increasing the protective factors while at the same time decreasing or minimizing the risk factors (Abraham, Pamela, and Kimani, 2012). Based on the modified social stress model, in case there are many risk factors that are present in the life of an individual, they are therefore highly likely to begin abusing drugs (Goyal, 2005). The continued availability of those risk factors leads to the intensification and addiction to alcohol and drugs. Some of the risk factors that are identified in this model include stress, which in the high school context can result from adolescent developmental changes or precious from home or school environment (Shukla, 2005).

The other risk factors include the normalization of alcohol and substance use that is justified by true legality and law enforcement. The availability and affordability of drugs also enable young people to start and continue using alcohol and other substances (Goyal, 2005). The advertising and promotion of alcohol through the media is another risk factor, including cultural practices and values that include the use of alcohol and other substances which invariably expose adolescents. Another risk factor can be in the form of the experience that the youth derive from using drugs, which could be positive in case they are using drugs to escape from immediate life stressors and therefore encourage them to continue using them (Abraham, Pamela, and Kimani, 2012).

Makau, Kaaria, and Katiba (2019) note that young smokers go through various stages, with each being influenced by different factors. There is the precontemplation stage in which the person is exposed to messages about using a particular drug. Advertising, family members, movies, role models, and peers are quite instrumental in this phase as they help the person develop convictions about using the 
drug. At the second stage, they contemplate the messages they have received over time and the behavior by their friends reinforces their decision to experiment with the drugs.

The modified social stress model also indicates that in cases where the protective factors are present, there is a significantly reduced chance for an individual to begin indulging in alcohol and other substances. The model identifies protective factors as including the attachments with people in the family, institutions, and peers such as school and religion who do not use alcohol or other substances (Abraham, Pamela, and Kimani, 2012). Other protective factors include skills which could be in terms of physical and performance capabilities that help individuals to manage stress and navigate peer pressure, thereby reducing the incidence of experimenting with drugs as a way of finding personal identity or attaching oneself to the wrong company (Goyal, 2005). The availability of resources within the environment or within the person also plays an integral role in helping them to meet their physical and emotional needs and therefore find no need to seek drug dependence. Examples of this include religious faith, positive

\section{RESULT AND DISCUSSIONS}

\section{Table 1: Drug Abuse in Various Regions in Kenya}

\begin{tabular}{ll}
\hline Region & Percentage Usage \\
\hline Lower eastern & 20.7 \\
Central & 17.4 \\
Upper eastern & 12.6 \\
Nyanza & 9.7 \\
Nairobi & 7.6 \\
North rift & 6.8 \\
Coast & 6.3 \\
Western & 6.0 \\
South rift & 4.2 \\
North eastern & 0.3 \\
\hline
\end{tabular}

Source: NACADA

Table 2: Drug usage in High School

\begin{tabular}{ll}
\hline High School Class & Percentage Usage \\
\hline Form One & $2.3 \%$ \\
Form Two & $8.1 \%$ \\
Form Three & $13.9 \%$ \\
Form Four & $12.7 \%$ \\
\hline
\end{tabular}

role models, guiding and counseling services, and anti-drug use campaigns (Shukla, 2005).

The model, therefore, suggests that understanding drug use problems in society involves taking into account both the risk factors and the protective factors at the same time. This is because the possibility of people becoming drug users is determined by either of the factors (Goyal, 2005). This model is effective in outlining some of the interventions that can be used to help students who are already abusing drugs and also in developing measures that could discourage students from using drugs (Abraham, Pamela, and Kimani, 2012).

\section{METHODOLOGY}

The researcher used a survey study. The respondents were drawn from stratified regions. The selected regions were Coast, Nyanza, and Nairobi. The schools sampled were registered with the Ministry of Education Science and Technology. They were categorized into national, county, and sub-county schools, boys and girls, mixed boarding, and mixed schools. Questionnaire and in-depth interviews were used to collect quantitative data from students and teacher 
East African Journal of Arts and Social Sciences, Volume 3, Issue 1, 2021

Article DOI: https://doi.org/10.37284/eajass.3.1.428

Table 3: When Students Are Likely to Use Alcohol and Drugs

\begin{tabular}{ll}
\hline Occasion & Percentage Usage \\
\hline During School Holidays & $48.5 \%$ \\
On their way Home & $35.1 \%$ \\
During School Trips & $31.4 \%$ \\
Weekends at School & $30.4 \%$ \\
During inter-school Meetings & $27.8 \%$ \\
During Entertainment in Schools & $24.4 \%$ \\
During Games & $23.7 \%$ \\
During Morning/Evening Preps & $15.4 \%$ \\
Brought During School Visits & $13.5 \%$ \\
During Class Breaks & $13.2 \%$ \\
Anytime & $9.7 \%$ \\
\hline
\end{tabular}

Table 4: Presence and Adequacy of Supervision Provided in School

\begin{tabular}{lll}
\hline & YES & NO \\
\hline Presence and Adequacy of Supervision at School & $72.6 \%$ & $27.4 \%$ \\
\hline
\end{tabular}

Table 5: Discussions with Friends on social media Regarding Alcohol and Drugs

\begin{tabular}{lllllll}
\hline & Frequency & & & \\
\cline { 2 - 5 } & Sometimes & Rarely & Never & $\begin{array}{l}\text { Very Often/ } \\
\text { Always }\end{array}$ & Rarely \\
\hline $\begin{array}{l}\text { Discussions with friends on social media } \\
\text { regarding alcohol and drugs }\end{array}$ & $29.1 \%$ & $21.5 \%$ & $23.4 \%$ & $14.4 \%$ & $11.7 \%$ \\
\hline
\end{tabular}

The study analysis is made from the report generated by NACADA, which is available, online as well as part of their reports. Such reports are comprehensive in their findings and so make reliable data for analysis. The report shown in Table $l$ on drug abuse in various regions in Kenya shows the impact rate of drug abuse in different places. The leading area of drug abuse is seen from the people from Lower eastern (20.7\%), Central (17.4\%), and upper eastern (12.6\%). From the report, Nyanza, Nairobi, and the coast have also been featured in the report with rates of $9.7 \%, 7.6 \%$, and $6.3 \%$ respectively.

Table 2 on drug usage in high school shows its correspondence on the high school level which is form one, two, three, and form four. From the report, drug usage is rampant with the form threes $(13.90 \%)$ followed by $12.70 \%$ who are form fours, the least are the form ones who are $2.30 \%$.

Table 2 shows when students are likely to use alcohol and drugs. The report shows that during school holidays, the students are more susceptible to the abuse of drugs followed by during school trips seen from $48.5 \%$ and $35.1 \%$ respectively. The least is seen to be anytime, which is $9.7 \%$. Others are the abuse of drugs during school trips (31.4\%), weekends at school $(30.4 \%)$, during inter-school meetings (27.8\%), during entertainment in school (24.4\%), during games $(23.7 \%)$, during morning and evening preps $(15.4 \%)$ and during class breaks $(13.2 \%)$

Table 4 shows the presence and adequacy of supervision provided in school. Majority of the respondents do admit that there is a presence and adequacy of supervision provided in school $(72.6 \%)$.

The researcher sought to find out whether discussions with friends on social media regarding alcohol and drugs provide an avenue for the abuse of drugs. From the respondents, $29.1 \%$ do say that sometimes it does, as $23.4 \%$ admit that it never does 
it. $21.5 \%$ do say that it rarely does, $14.4 \%$ say it does always, and $11.7 \%$ say it often does (Table 5).

\section{CONCLUSION}

The teens of the age 13 to 15 are the prone group to the abuse of drugs. The teen's abuse of drugs is well observed to be abused both at home and in school. The transition of the use of drugs is wellcoordinated from home and school. The peers are the most influential in the abuse of drugs. Abuse of drugs is well known to most of the respondents in school. Without close monitoring of the teens by the parents and the teachers brings such abuses which later results to uncontrolled behavior of which some may become resistant to reforms

\section{RECOMMENDATION}

The introduction of the county government has brought home the contact of the villages with the authority. This means that people having been implicated having abused drugs can be easily noted and rehabilitated most especially the youths and students. In this regard, rehabilitation centers, as well as special schools or social education halls, have to be built to take care of the youth that is already affected. The county government that is in charge of drugs control, the NGOs, NACADA, FBOs, CBOs, politicians, teachers, and local leaders should be in a position to come up with amicable approaches that can allow the youths to appreciate the dangers and effects associated with substances and drugs.

Guidance and counseling, expedited by the nongovernmental organization is a prime approach available to curb drug abuse in public schools in Kenyan, churches, and homes which are the common social environment for the youths and children. The guidance and counseling teachers should endeavor to better their understanding of their pupils and students through in-service education programs done by the external guest speakers to ensure that they don't involve themselves in such damaging activities as drug abuse. The school administration should strengthen their understanding of the students' family background, peer groups, past discipline records, etc. this will then aid the administration to come up with methods of making sure that each pupil or student in their respective institutes is not prone to indulging in drug usage.

Parents should take more attention to students' academic abilities pursuits, interests, and potentialities. These will in the process assist the parents to understand and advise him/her about the significance of focusing on academics and avoiding lures of testing with drugs. Government should put stringent disciplinary actions on drug brokers and suppliers, particularly those found availing drugs and related ingredients to minors. The government should also control the selling of common drugs in marketplaces and shops to protect the pupils or students among other susceptible persons.

\section{REFERENCES}

Abraham, T. S., Pamela, O., and Kimani, C. G. (2012). Techniques Used In Managing Drug Abuse In Secondary Schools In Kenya. Lap Lambert Academic Publishing GmbH KG.

Abur, J. O. (2014). Drug and Substance Abuse Among Secondary School Students, In Embakasi District, Nairobi County. University of Nairobi.

Cheloti, S. K., and Gathumbi, A. M. (2016). Curbing Drug and Substance Abuse in Secondary Schools in Kenya; The Disconnect in School Community Intervention Strategies. Educational Technology, 95 , 40881-40888.

Fatoye, F. O., \& Morakinyo, O. (2002). Substance use among secondary school students in rural and urban communities in South Western Nigeria. East African medical journal, 79(6), 299-305.

Goyal, O. P. ( 2005). Anti-social Patterns of Begging and Beggars. Delhi : Isha Books.

Hibbel, B., Anderson, B., Bjarnason, T., Kokkeri, A., Morgan, M., \& Narusk, A. (1995). Alcohol and other drug use among medical students in 26 European countries. The European schools project on alcohol and other drugs (ESPAD) study, Stockholm, Council of Europe.

Joseph, K. (2019). The Effects of Drug and Substance Abuse in Secondary Schools: The Case of Garissa County, Kenya. African Journal 
of Education, Science and Technology, 5(2), 260 -270 .

Kimanthi, M. M., and Thinguri, R. (2014). Drug Abuse Among Students In Public Secondary Schools In Kenya, The Case Of Kitui County, Kenya. Researchjournali's Journal of Education, 2(11).

Makau, B. J., Kaaria, Z., and Katiba, D. (2019). Challenges Experienced In Drug And Substance Abuse Cessation Efforts Among Students In Secondary Schools: A Case Of Machakos Municipality, Machakos County, Kenya. International Journal of Psychology, 3(1), 1-11.

Mpabulungi, L., \& Muula, A. S. (2004). Tobacco use among high school students in Kampala, Uganda: questionnaire study. Croat Med $J, 45(1), 80-3$.

Ngesu, L. M. (2017). Drugs and Substance Abuse in Kenyan Secondary Schools: Is It a Reality? Journal of Educational Research, 2(3), 182 190.

Njeri, N. A., and Ngesu, L. (2014). Causes and Effects Of Drug And Substance Abuse Among Secondary School Students In Dagoretti Division, Nairobi West District-Kenya. Global Journal of Interdisciplinary Social Science , 3(3), 1-4.

Njoki, K. M. ( 2013). Drug and Substance Abuse in Secondary Schools in Kenya: A Case Study of Kiambu County. University of Nairobi.

Odhiambo, O. D., Sifuna, D. N., and Kombo, D. K. (2019). Contributing Factors to Drug Abuse among Girls in Secondary Schools in Nakuru County, Kenya. The International Journal Of Humanities and Social Studies, 107 - 120.

Rugendo, M. M. (2016). Assessing Substance Abuse Among Secondary School Students in Kendu Zone, Homabay County, Kenya. Journal of Health, Medicine and Nursing, 24.

Shukla, P. C. (2005 ). Street children and the asphalt life. Delhi: Isha Books . 